\title{
Aspirin inhibits proliferation of gemcitabine-resistant human pancreatic cancer cells and augments gemcitabine-induced cytotoxicity
}

\author{
Yan-qiu OU\#, Wen bo ZHU\#, Yan LI", Peng-xin QIU, Yi-jun HUANG, Jun XIE, Song-min HE, Xiao-ke ZHENG, Tian-dong LENG,
} Dong XU, Guang-mei YAN*

Department of Pharmacology, Zhong-shan Medical College, Sun Yat-Sen University, Guangzhou 510089, China

Aim: To investigate whether aspirin is able to augment gemcitabine-induced cytotoxicity in human pancreatic cancer cells.

Methods: Two gemcitabine-insensitive human pancreatic cancer cell lines, PANC-1 and Capan-1, were used. Cells were treated with either aspirin or gemcitabine alone or both of them. Cell growth and apoptosis were determined by MTT assay, Annexin V or Hoechest 33258 staining. Cell cycle distribution was examined by flow cytometry. Western blot with specific phosphorylated protein antibodies was used to detect the activation of protein kinase. RT-PCR and Western blot were applied to assess the transcription and protein level for cyclin D1 and Bcl-2.

Results: Aspirin alone significantly inhibits the proliferation of PANC-1 cells by causing cell cycle arrest at $\mathrm{G}_{1}$ phase. Aspirin potentiates the anti-survival effect of gemcitabine as well as its pro-apoptotic effect in PANC-1 cells, although aspirin per se does not trigger apoptosis. Aspirin inhibits GSK-3 $\beta$ activation and suppresses the expression of its downstream gene products (cyclin D1 and Bcl-2), which are implicated in proliferation, survival and chemoresistance of pancreatic cancer. The effects of aspirin on Capan-1, were similar to that on PANC-1.

Conclusion: Our results suggest that aspirin inhibits the proliferation of gemcitabine-resistant pancreatic cancer cells and augments the antisurvival effect of gemcitabine, probably by suppressing the activity of GSK-3 $\beta$ and its downstream gene products.

Keywords: aspirin; human pancreatic cancer; gemcitabine; apoptosis; GSK-3ß; cyclin D1; Bcl-2

Acta Pharmacologica Sinica (2010) 31: 73-80; doi: 10.1038/aps.2009.172; published online 7 December 2009

\section{Introduction}

Pancreatic cancer remains a fatal disease with a 5-year survival rate less than $5 \%{ }^{[1]}$. Besides surgery and radiation, chemotherapy regimens often fail to improve the outcome of pancreatic cancer patients. Currently, gemcitabine (difluorodeoxycytidine) appears to be the best chemotherapeutic agent in the treatment of advanced pancreatic cancer ${ }^{[2]}$. However, even with this drug, the objective tumor response rate is less than $10 \%$, and the impact of the drug on survival is minor ${ }^{[3]}$. Moreover, gemcitabine is associated with drug resistance and highly toxic for tumor cells as well as normal cells ${ }^{[2,4]}$. Thus, there is a need for novel strategies involving less toxic agents that can sensitize pancreatic cancer cells to chemotherapy.

The transcription factor nuclear factor- $\mathrm{KB}(\mathrm{NF}-\mathrm{kB})$ plays

\footnotetext{
\# These authors contributed equally to this work.

* To whom correspondence should be addressed.

E-mail ygm@mail.sysu.edu.cn

Received 2009-07-10 Accepted 2009-11-04
}

a major role in promoting gemcitabine resistance ${ }^{[2]}$, because NF- $\mathrm{KB}$ mediates transcription of a serial of proliferation and antiapoptosis genes, such as cyclin D1 and Bcl-2. Recent evidence indicates that glycogen synthase kinase-3 $\beta$ (GSK-3 $\beta$ ) positively regulates $\mathrm{NF}-\mathrm{kB}$-mediated gene transcription and cell survival ${ }^{[5,6]}$. It is reported that pancreatic cancer cells contain a pool of active GSK-3 $\beta$ and that pharmacologic inhibition of GSK-3 $\beta$ kinase activity using small molecule inhibitors or genetic depletion of GSK-3 $\beta$ by RNA interference influences NF-kB-mediated gene (such as cyclin D1, Bcl-2) transcription, leading to decreased cancer cell proliferation and survival. Together, this evidence suggests GSK-3 $\beta$ as a potential therapeutic target in the treatment of pancreatic cancer. Therefore, agents that block GSK-3 $\beta$ activation could reduce chemoresistance to gemcitabine and perhaps be used in combination with gemcitabine as a novel therapeutic regimen for pancreatic cancer.

Aspirin (acetylsalicylic acid, ASA), the traditional nonsteroid anti-inflammatory drug (NSAID), is one such agent 
that is nontoxic to humans, which has become one of the most commonly utilized therapeutic drugs all over the world since its introduction into modern medicine in $1897^{[7]}$. Dihlmann ${ }^{[8]}$ suggested that ASA was able to induce phosphorylation/ inactivation of GSK-3 $\beta$ in several colon cancer cell lines. Nevertheless, the effect of ASA on GSK-3 $\beta$ activity in pancreatic cancer cells is never, to our knowledge, investigated before. In addition, although previous studies report that ASA is capable of suppressing pancreatic cancers growth in vitro and in vivo ${ }^{[9]}$, the exact function and the underlying mechanism of ASA on pancreatic cancer remain to be further explored.

Thus, the goal of this study was to investigate the impact of ASA on the growth of human pancreatic cancer cells. Additionally, we investigate whether ASA can potentiate the gemcitabine-induced cytotoxicity in pancreatic cancer cells in vitro.

\section{Materials and methods}

\section{Cell culture and drug treatment}

Human pancreatic cancer cell line PANC-1, Capan-1 were obtained from Shanghai Cell Bank and maintained in DMEM (Invitrogen, Grand Island, NY) supplemented with 10\% fetal bovine serum (FBS, Invitrogen), $100 \times 10^{3} \mathrm{U} / \mathrm{L}$ penicillin, and $100 \times 10^{3} \mathrm{U} / \mathrm{L}$ streptomycin in $5 \% \mathrm{CO}_{2}$ at $37^{\circ} \mathrm{C}$. Human pancreatic cancer cell line PANC-1, Capan-1 were chosen as in vitro model, because they are considered relatively resistant to many chemotherapeutic regimens ${ }^{[10]}$. ASA (Sigma, St Louis, Mo) was dissolved in DMSO (Sigma) and diluted with DMEM medium to a final concentration of $1 \%$ DMSO. The $\mathrm{pH}$ value of the ASA-containing medium was adjusted to 7.2 with $2.8 \%$ $\mathrm{NaHCO}_{3}$ (Shanghai Sangon Biological Engineering Technology \& Services Co, Ltd, China). Vehicle was treated with an equivalent volume of 10\% FBS-medium with 1\% DMSO. Gemcitabine (difluorodeoxycytidine, Lilly, Bad Homburg, Germany) was stored at $4{ }^{\circ} \mathrm{C}$ and dissolved in PBS on the day of use.

\section{Cell growth and survival assays}

All assays were carried out in quintuple of three separate experiments. Cell growth was tested by 3-(4,5-dimethylthiazol-2-yl)-2,5-diphenyl-tetrazolium bromide (MTT, Sigma) assay. Apoptosis was evaluated with Annexin V-fluoroisothiocyanate apoptosis detection kit according to the instruction of the manufacturer (Sigma) and analyzed with use of a EPICS ALTRA flow cytometer (Beckman Coulter, Fullerton, CA) and CellQuest software as previously described ${ }^{[11]}$. Apoptosis was observed by Hoechst 33258 staining as described ${ }^{[12]}$. Apoptotic cells were characterized by morphological alteration as condensed nuclei and cell shrinkage. Necrosis was assayed using the CytoTox96 non-radioactive cytotoxicity assay kit (Promega, Madison, WI), which quantifies cell death and cell lysis, based on the measurement of lactate dehydrogenase (LDH) activity released from the cytosol of damaged cells into the supernatant.

\section{Cell cycle analysis}

Cell cycle was assessed as previously described ${ }^{[13]}$ with minor modifications. Briefly, cells were plated in parallel in $35-\mathrm{mm}^{2}$ culture plates at a concentration of $8 \times 10^{5}$ cells per plate. After $24 \mathrm{~h}$ of serum starve, cells were exposed to $10 \%$ FBS-medium with/without $4 \mathrm{mmol} / \mathrm{L}$ ASA for various durations and then were harvested by trypsinization, washed in cool PBS twice and fixed in $75 \%$ ethanol overnight in $4{ }^{\circ} \mathrm{C}$. After that, cells were incubated in solution with DNA-binding dye propidium iodide (PI, $50 \mathrm{~g} / \mathrm{L})$, RNase $\left(4 \times 10^{3} \mathrm{kU} / \mathrm{L}\right), \mathrm{NaF}(0.3 \mathrm{~g} / \mathrm{L})$ and sodium citrate $(1 \mathrm{~g} / \mathrm{L})$ for $30 \mathrm{~min}$ at $37^{\circ} \mathrm{C}$ in the dark. Finally, red fluorescence from $488 \mathrm{~mm}$ laser-excited PI in every cells was analyzed by EPICS ALTRA flow cytometer (Beckman Coulter, Fullerton, CA) using a peak fluorescence gate to discriminate aggregates. The percentage of cells in $G_{0} / G_{1}, S$ and $\mathrm{G}_{2} / \mathrm{M}$ was determined from DNA content histograms by Multicycle for windows (Phoenix Flow Systems, San Diego, CA).

\section{Preparation of nuclear extracts}

PANC-1 cells were incubated with different concentrations of ASA for $24 \mathrm{~h}$, followed by preparation of nuclear extracts using nuclear extract kit (Pierce, IL) according to the manufacturer's instructions. In brief, about $3 \times 10^{6}$ cells per sample were washed with ice-cold PBS/phosphate inhibitors, scraped, and collected by centrifugation at $500 \times g$ for $5 \mathrm{~min}$. The pellets were suspended in $500 \mu \mathrm{L}$ of hypotonic buffer, incubated on ice for $15 \mathrm{~min}$ and centrifuged at $14000 \times \mathrm{g}$ for $30 \mathrm{~s}$ at $4{ }^{\circ} \mathrm{C}$. The supernatant (cytosolic extract) was removed and the pellet (nuclear fraction) was suspended in $50 \mu \mathrm{L}$ of complete lysis buffer and incubated on ice for $30 \mathrm{~min}$ with frequent mixing. Finally the suspension was centrifuged at $14000 \times \mathrm{g}$ for $10 \mathrm{~min}$ at $4{ }^{\circ} \mathrm{C}$ and the supernatant (nuclear extract) was subjected to Western blot analysis.

\section{Western blot analysis}

Western blot was performed as previously described ${ }^{[13]}$. The following antibodies were used: antibody against PCNA (1:15000, Cell Signaling Technology, Beverly, MA), GAPDH, cyclin D1, Bcl-2, GSK-3 $\beta$, phosphor-GSK-3 $\beta$-Ser9, Akt, phosphor-Akt-Ser473 (1:1000, Cell Signaling Technology), phosphor-PP2A-Tyr307 (1:1000, Santa Cruz Biotechnology, Santa Cruz, CA), PP2A (1:1000, Millipore, Billerica, MA), $\beta$-actin (1:1000, Thermo Scientific IHC, Fremont, CA) and C23 (also as designated nucleolin, 1:1000, Santa Cruz Biotechnology).

\section{Reverse transcription-polymerase chain reaction (RT-PCR)}

Total RNA was isolated with TRIzol reagent (Gibco-BRL) according to the manufacturer's instructions. Complementary DNA was synthesized from $1 \mu \mathrm{g}$ of total RNA by reverse transcription using the Superscript ${ }^{\mathrm{TM}}$ II reverse transcriptase kit (Gibco-BRL). Sequence of the PCR primers: GAPDH: 5'-CCACCCATGGCAAATTCCATGGCA-3' (sense primer), 5' -TCTAGACGGCAGGTCAGGTCCACC-3’ (antisense primer). Cyclin D1: 5'-GTCACACTTGATCACTCTGG-3' (sense primer), 5' -TGGCCATGAACTACCTGGA-3' (antisense primer). Bcl-2: 5'-GTGGAGGAGCTCTTCAGGGA-3' (sense primer), 5'-CGGTGCTTGGCAATTAGTGG-3' (antisense primer). The PCR conditions contained an initial cDNA synthesis reaction 
at $42{ }^{\circ} \mathrm{C}$ for $1 \mathrm{~h}$, followed by a denaturation step for $5 \mathrm{~min}$ at $94{ }^{\circ} \mathrm{C}$ and 22 cycles: $30 \mathrm{~s}$ at $94{ }^{\circ} \mathrm{C}, 30 \mathrm{~s}$ at $50{ }^{\circ} \mathrm{C}$ and $30 \mathrm{~s}$ at $72{ }^{\circ} \mathrm{C}$. After the last cycle a final extension was performed at $72{ }^{\circ} \mathrm{C}$ for $10 \mathrm{~min}$.

\section{Statistics}

Data are presented as mean \pm SEM for three separate experiments. $P<0.05$ was considered significant using Student's $t$ test.

\section{Results}

\section{ASA inhibits the growth of PANC-1 cells in vitro}

Initially, we determined the effect of ASA on the growth of PANC-1 cells using MTT assay. As the growth curve shown, ASA treatment attenuates the growth rate of PANC-1 cells time- and dose-dependently (Figure 1). Compared with the untreated cells, $4 \mathrm{mmol} / \mathrm{L}$ ASA is sufficient to inhibit the cell growth by about $40 \%(P<0.01)$ at $24 \mathrm{~h}$, and the inhibitory effect of ASA becomes more significant at $72 \mathrm{~h}$. Clearly, ASA alone is able to slow down the growth of PANC-1 cells.

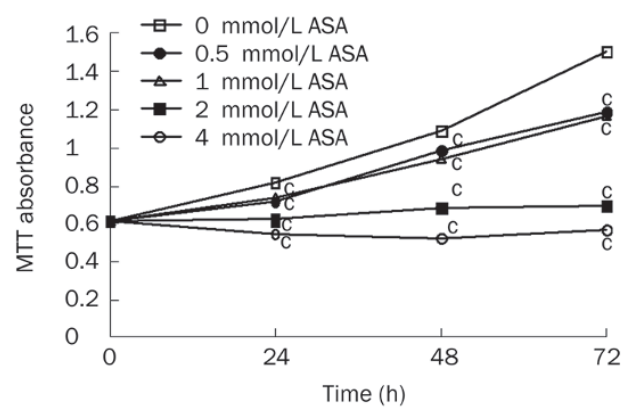

Figure 1. ASA inhibits growth of PANC-1 cells. Cells were treated with various concentrations of ASA and cell growth was determined using the MTT assay at 24, 48, and $72 \mathrm{~h}$. Results represent the mean absorbance at $570 \mathrm{~nm}$ of three different experiments with quintuple wells. SEM bars are not included for clarity. ${ }^{c} P<0.01$ compared with untreated cells at all time points.

\section{ASA decreases proliferation instead of inducing apoptosis or necrosis in PANC-1 cells}

The reduction in growth of PANC-1 cells in response to ASA could be explained either by increased cell death or by reduced cell proliferation. Thus, the level of proliferating cell nuclear antigen (PCNA), an established index for proliferation cells, was firstly assessed to determine cell proliferation in PANC-1 cells $^{[14]}$. Western blot analysis clearly shows that PCNA protein expression undergoes a down-regulation change in a time-dependent manner after exposure to ASA (Figure 2A). Secondly, Anexin V, Hoechst staining and LDH examination were used to investigate whether treatment of ASA causes apoptosis or necrosis. There was no increase of Anexin V positive cells after ASA treatment during $24 \mathrm{~h}$ to $72 \mathrm{~h}$ (Figure 2B). Meanwhile, Apoptotic bodies are not observed in either
A

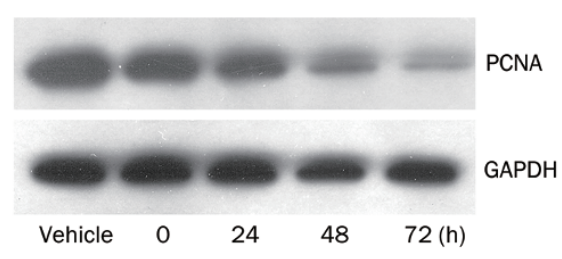

B
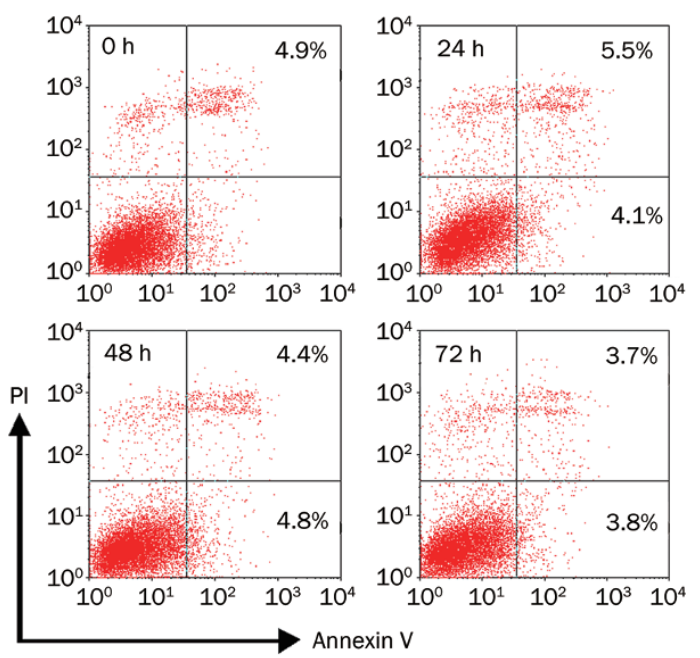

C
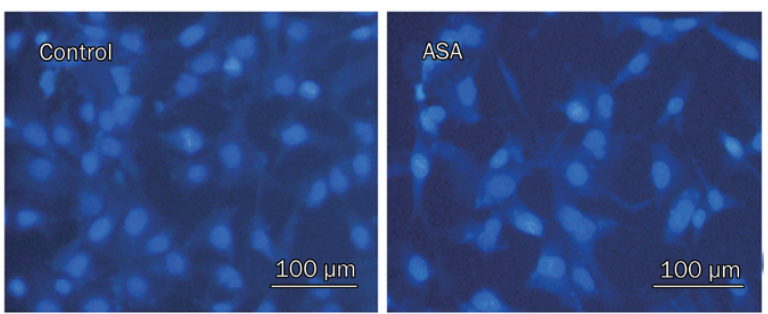

D

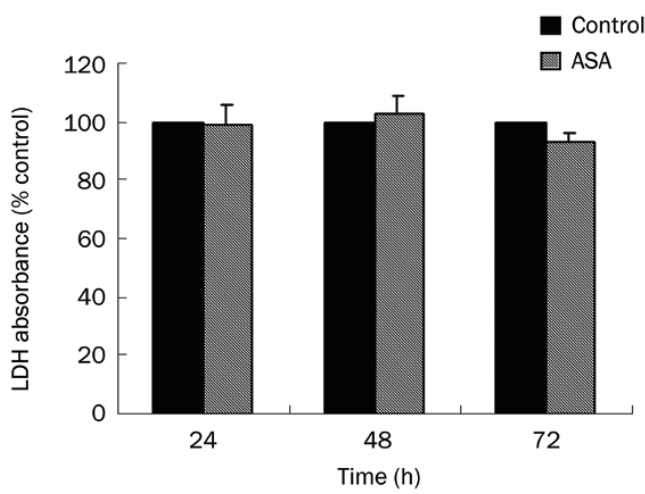

Figure 2. Effect of ASA on PANC-1 cells proliferation, apoptosis and necrosis. (A) PANC-1 cells were treated with $4 \mathrm{mmol} / \mathrm{L}$ ASA for various time and cell lysates were subjected to Western blot using anti-PCNA and anti-GAPDH antibodies. (B) AnnexinV/propidium iodide double staining for apoptosis assay. (C) Fluorescent staining of nuclei by Hoechst 33258 in PANC-1 cells treated with or without $4 \mathrm{mmol} / \mathrm{L}$ ASA for $24 \mathrm{~h}$. (D) PANC-1 cells were incubated with $4 \mathrm{mmol} / \mathrm{L}$ ASA for the indicated time and cultured medium was collected for LDH release assay. Results represent the mean of three different experiments with quintuple wells. 
ASA-treated or untreated cells (Figure 2C). And there is not any statistically significant difference in the mean LDH absorbance between ASA-treated and untreated cells during the time course of $24 \mathrm{~h}$ to $72 \mathrm{~h}$ (Figure 2D). Hence, cytotoxicity is not contributing to the reduction in cell growth. Therefore, we strongly believe that the inhibitory effect of ASA on PANC-1 growth is based on the reduction of proliferation instead of induction of cell death.

ASA causes cell cycle arrest at $G_{1}$ phase and decreases $S$ phase fraction in PANC-1 cells

To determine the mechanism involved in the reduction of cell proliferation, we analyzed the cell cycle distributions of PANC-1 cells treated by ASA. ASA hampers the cell cycle progression by arresting up to three quarters of cancer cells at $\mathrm{G}_{1}$ phase, and by decreasing $S$ phase fraction by about $40 \%$ in $24 \mathrm{~h}$ compared with the control (Figure 3). Additionally, no subdiploid (sub-G $\mathrm{G}_{0} / \mathrm{G}_{1}$ ) peak in DNA content histograms is obtained by flow cytometry, which further supports the findings mentioned above that no apoptosis is induced by ASA.
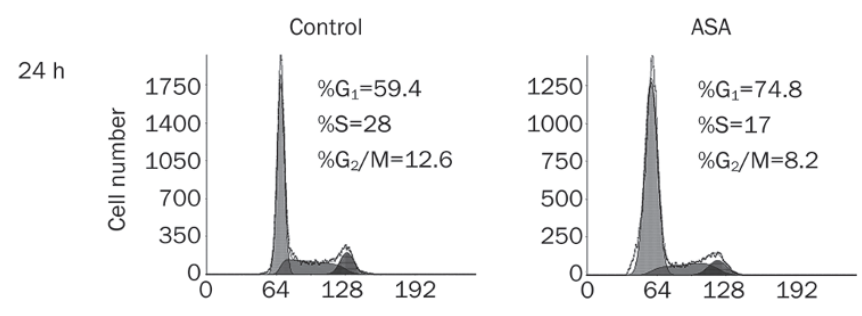

$48 \mathrm{~h}$
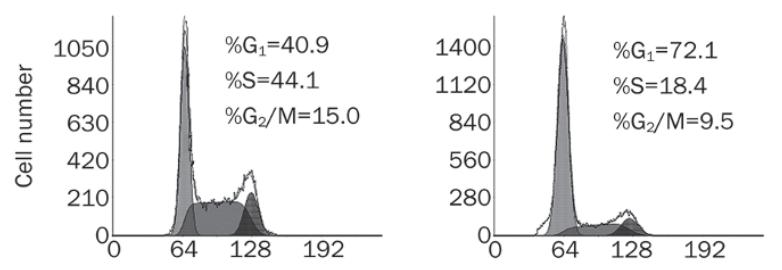

$72 \mathrm{~h}$
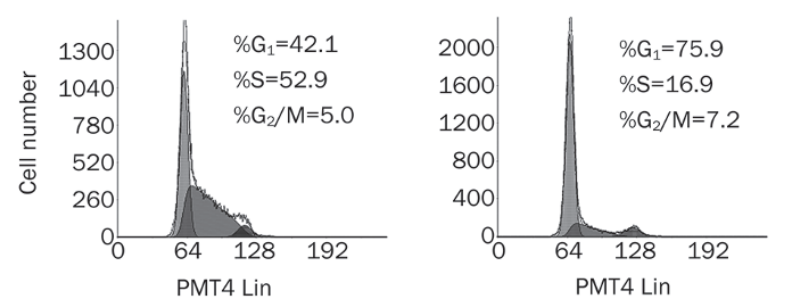

Figure 3. Cell cycle distributions in ASA-treated PANC-1 cells. PANC-1 cells were treated with or without $4 \mathrm{mmol} / \mathrm{L}$ ASA for various time and cell cycle analysis was performed using the fluorescent cytometry.

ASA augments the effect of gemcitabine on cell survival and induction of apoptosis in PANC-1 cells

To determine the effect of ASA on gemcitabine-induced cytotoxicity, PANC-1 cells were treated with gemcitabine in the presence of ASA. Only minor reduction of cell survival was observed with the treatment of gemcitabine alone at the dose of $0.2 \mu \mathrm{mol} / \mathrm{L}$ to $20 \mu \mathrm{mol} / \mathrm{L}$ in $24 \mathrm{~h}$ (Figure 4A). Obviously, human pancreatic PANC-1 cells are not sensitive to gemcitabine treatment, which is consistent with the previous report ${ }^{[10]}$. However, ASA significantly promotes gemcitabineinduced cytotoxicity, which is dependent upon concentrations of ASA and gemcitabine $(P<0.05)$. Similar results were observed with Hoechst staining. Data from Hoechst assays (Figure 4B) show that ASA pronouncedly increased the apoptotic effect of gemcitabine, whereas gemcitabine alone, has minimal apoptotic effect on the PANC-1 cells.
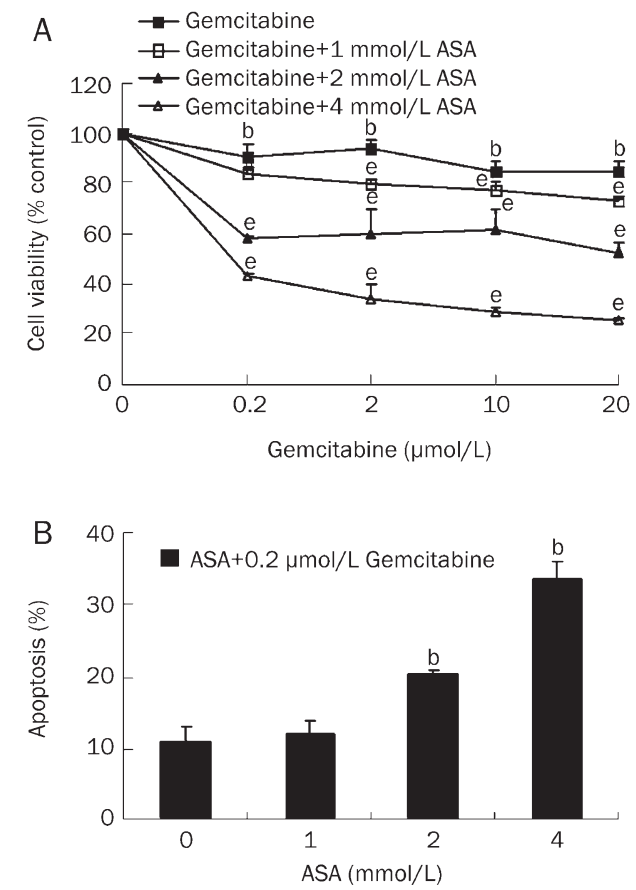

Figure 4. ASA augments the anti-survival and pro-apoptosis effects of gemcitabine on PANC-1 cells. (A) Cells were treated with various concentrations of gemcitabine in the presence/absence of indicated concentrations of ASA for $24 \mathrm{~h}$ and cell growth was measured by MTT assay. Data are expressed as percentage of cell growth observed in untreated cultures. Results represent the mean of three different experiments with quintuple wells. ${ }^{\mathrm{b}} P<0.05$ compared with untreated cells; ${ }^{\text {e }} P<0.05$ compared with gemcitabine alone-treated cells at corresponding concentrations. (B) Cells were treated with various concentrations of ASA in combination with $0.2 \mu \mathrm{mol} / \mathrm{L}$ gemctitabine for $24 \mathrm{~h}$. Apoptosis was then determined by Hoechst 33258 assay. ${ }^{b} P<0.05$ compared with 0.2 $\mu \mathrm{mol} / \mathrm{L}$ gemcitabine-treated cells.

\section{ASA inhibits GSK-3 $\beta$ activation in PANC-1 cells}

To explore the molecular mechanism underlying the above effect of ASA on PANC-1 cells, we investigated whether the effect of ASA is associated with the inhibition of GSK-3 $\beta$ activation. Using Western blot analysis of total cell proteins, we observed that ASA dose-dependently increased phosphorylated level of GSK-3 $\beta$ at Ser9, which represents the inactive form of GSK-3 $\beta$ kinase, while has no effect on the total level of 
GSK-3 $\beta$ (Figure 5A). To exactly verify whether this alteration takes place in the nucleus, we replicated the experiment using nuclear extracts. Interestingly, the change of GSK-3 $\beta$ activation in nuclear fractions followed a similar pattern to that in total extracts (Figure 5B). Thus, we identified that GSK-3 $\beta$ is inactivated by ASA in the nucleus of PANC-1 cells.

A

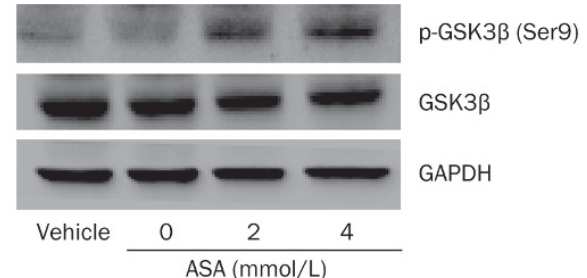

B

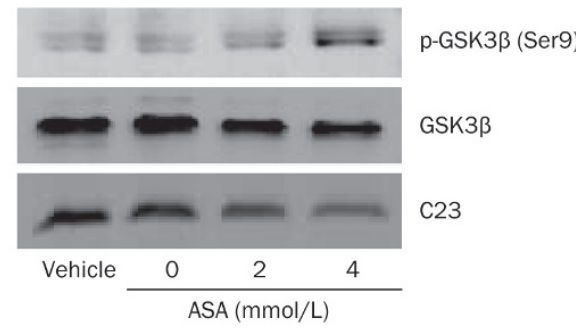

C

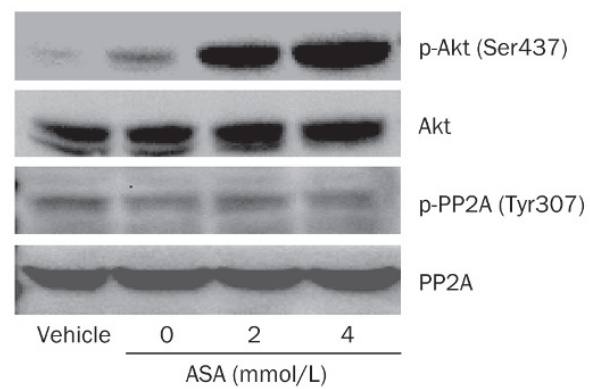

Figure 5. Inactivation of GSK-3 $\beta$ by ASA. Cells were treated with various concentrations of ASA for $24 \mathrm{~h}$. Total extracts $(\mathrm{A}, \mathrm{C})$ or nuclear extracts (B) were obtained and subjected to Western blotting analysis. GAPDH and C23 were loaded to normalized total and nuclear protein.

To further elucidate the signaling pathways that inactivate GSK-3 $\beta$, we examined the effect of ASA on Akt and PP2A, which are both implicated in the regulation of GSK-3 $\beta$ activity $^{[15]}$. In untreated PANC-1 cells, phosphorylated Akt at Ser437 is marginal. After treatment with ASA for $24 \mathrm{~h}$, a very strong band of the phosphorylated Akt appeared (Figure 5C). Therefore, ASA stimulates Akt activation via protein phosphorylation at Ser437 provided that phosphorylation of the Ser437 residue is required for a maximal Akt activation ${ }^{[16]}$. On the other hand, ASA causes little change on the inactivated phosphorylation status of PP2A at Tyr307.

\section{ASA downregulates the expression of cyclin D1 and Bcl-2}

We then assessed the expression of cyclin D1, which plays important role in tumor cell proliferation and cell cycle progression from $G_{1}$ phase to $S$ phase; and Bcl-2, which is involved in tumor survival and chemoresistance in pancreatic cancer cells ${ }^{[17]}$, because both of the genes can be regulated by GSK-3 $\beta$ in pancreatic cancer cells ${ }^{[6]}$. RT-PCR analysis (Figure $6 \mathrm{~A}$ ) indicates that mRNA level of cylcin D1 and Bcl-2 are significantly suppressed by ASA in a dose-dependent manner in $24 \mathrm{~h}$. Western blotting (Figure 6B) shows that ASA also reduces the protein level of cyclin D1 and Bcl-2.

A

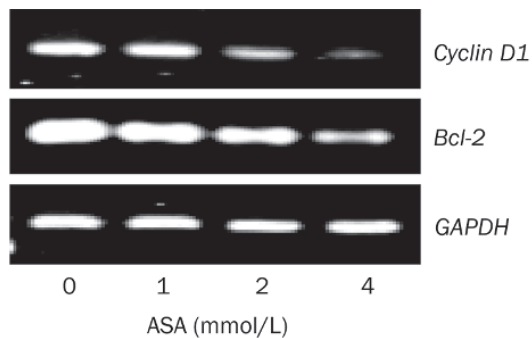

B

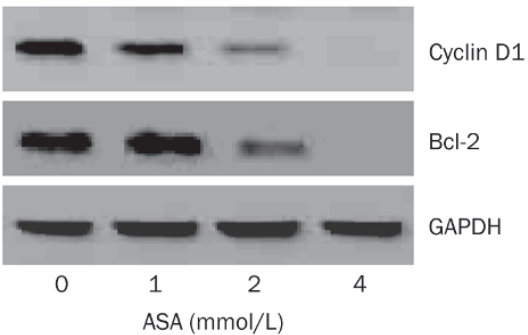

Figure 6. ASA downregulates the expression of cyclin D1 and $\mathrm{Bcl}-2$ in PANC-1 cells. PANC-1 cells were treated with various concentrations of ASA for $24 \mathrm{~h}$ and harvested for RT-PCR (A) or Western blotting analysis (B).

ASA inhibits growth, decreases $S$ phase accumulation, augments the effect of gemcitabine and represses GSK-3 $\beta$ activation in Capan- 1 cells

To test whether the effects of ASA in PANC-1 cells are cellspecific or not, another human pancreatic cancer cell line Capan-1 cells were used. ASA inhibits cell growth dose- and time-dependently in Capan-1 cells as in PANC-1 cells (Figure 7A). Moreover, $4 \mathrm{mmol} / \mathrm{L}$ ASA decreases $S$ phase accumulation time-dependently (Figure 7B). Furthermore, augment of gemcitabine-induced apoptosis by ASA was also seen in Capan-1 cells as in PANC-1 cells (Figure 7C). Mechanically, after treatment with ASA for $24 \mathrm{~h}$, the levels of GSK-3 $\beta$ and Akt phosphorylation displayed the same alteration panel as in PANC-1 cells (Figure 7D). These findings demonstrate that ASA may have a broad therapeutic potential in human pancreatic cancer cells.

\section{Discussion}

The aim of this study is to examine the effect of ASA on the growth of pancreatic cancer cells and determine whether ASA, the famous NSAID, can sensitize the cells to gemcitabine. We find that ASA alone inhibits the proliferation of human pancreatic cancer cells by hampering cell cycle progressing, and that ASA enhance the apoptotic effects of gemcitabine; these effects of ASA may be associated with suppression of the 
A
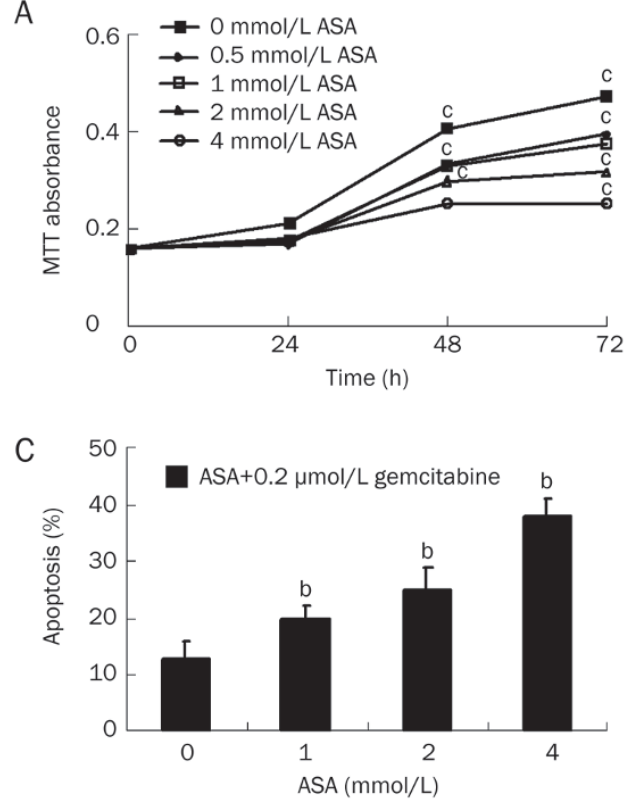

D

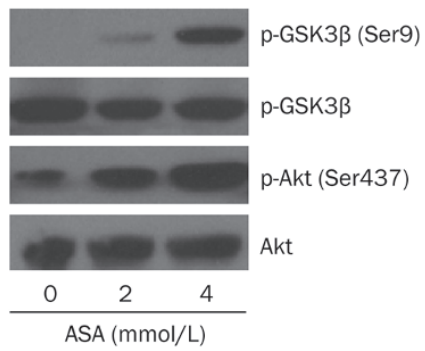

B
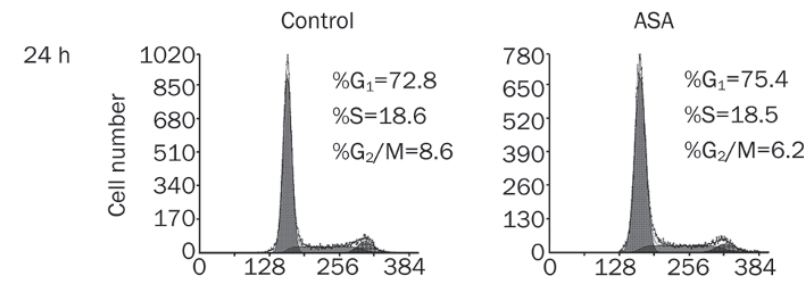

$48 \mathrm{~h}$
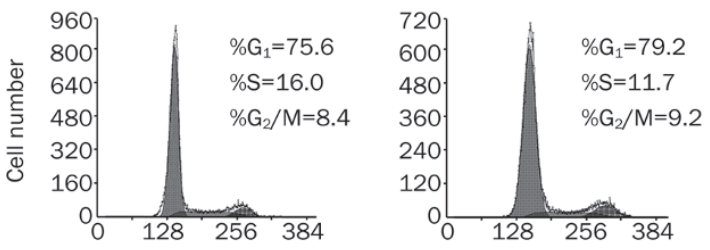

$72 \mathrm{~h}$

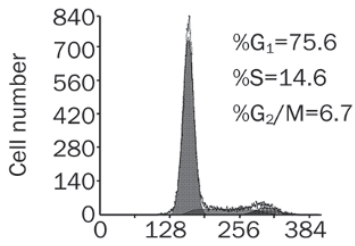

Figure 7. (A) Capan-1 cells were treated with various concentrations of ASA and cell growth was determined using the MTT assay at 24,48 , and $72 \mathrm{~h}$. Results represent the mean absorbance at $570 \mathrm{~nm}$ of three different experiments with quintuple wells. SEM bars are not included for clarity. ${ }^{\mathrm{C}} P<0.01$ compared with untreated cells at corresponding time points. (B) Capan-1 cells were treated with or without $4 \mathrm{mmol} / \mathrm{L}$ ASA for various time and cell cycle analysis was performed using the fluorescent cytometry. (C) Cells were treated with various concentrations of ASA in combination with $0.2 \mu \mathrm{mol} / \mathrm{L}$ gemctitabine for $24 \mathrm{~h}$. Apoptosis was then determined by Hoechst 33258 assay. ${ }^{\mathrm{b}} \mathrm{P}<0.05$ compared with $0.2 \mu \mathrm{mol} / \mathrm{L}$ gemcitabine-treated cells. (D) The effect of ASA on Akt/GSK-3ß signaling pathway in Capan-1 cells.

activity of GSK-3 $\beta$ and downregulation of cyclin D1 and Bcl-2. These findings extend our understanding of the function and molecular basis of ASA on the dismal disease.

ASA is a first-line medication in pancreatic cancer pain control, intended to keep patients comfortable without resorting to opioids ${ }^{[18,19]}$. Because high concentrations (1-5 mmol/L) of ASA are achievable in vivo by oral administration of ASA at 4-10 g/d during treatment of rheumatic disorder and arthritis $^{[20]}$, accumulating literature is evaluating additional, COX-independent, biological activities for these high doses of ASA.

Previous studies suggest that ASA is able to induce apoptosis in pancreatic cancer cells ${ }^{[9]}$. However, in our work, we demonstrated that ASA, even at its relative high dose (4 $\mathrm{mmol} / \mathrm{L})$, hardly causes apoptosis in PANC-1 cells. This was evidenced by the Annexin V and Hoechest 33258 staining and flow cytometry assays. The pronounced inhibition of growth of pancreatic cancer cells by ASA, is mainly due to the reduction of proliferation and retardation of cell cycle progression.

Gemcitabine alone only has a marginal effect on cell growth and apoptosis in PANC-1 cell line, which fits well with previous finding that PANC-1, Capan-1 cells are considered relatively resistant to many chemotherapeutic regimens ${ }^{[2,10]}$. However, ASA was shown to significantly enhance the apoptotic effect of gemcitabine in these cells. This finding is not contra- dictory to the previous report that combination of gemcitabine and celecoxib did not demonstrate significant improvement in patients with advanced pancreatic cancer ${ }^{[21]}$. Because PANC-1 and Capan-1 cells are cyclooxygenase-2-negative, most bioactivities of ASA on this cell line were thought to be COX-2independent.

The mechanism by which ASA exerts above bioactivity may involve the suppression of activity of GSK-3 $\beta$. Ougolkov ${ }^{[22]}$ have reported that GSK-3 $\beta$ aberrantly accumulates in human pancreatic cancer cells and its accumulation in cell nuclear is associated with its kinase activity and tumor differentiation. GSK-3 $\beta$ positively regulates the activity of NF-kB, while NF-KB per se plays a pivotal role in promoting gemcitabine resistance in pancreatic cancer ${ }^{[2]}$, so it is very likely that the inactivation of GSK-3 $\beta$ by ASA can sensitize the cells to gemcitabine. This hypothesis was evidenced by the finding that $\mathrm{LiCl}$, the pharmacological inhibitor of GSK-3 $\beta$, can significantly sensitize PANC-1 or Capan-1 cells to gemcitabine-induced apoptosis (Supplementary Figure). Additional studies are needed to determine the necessary role of GSK-3 $\beta$ in the effect of ASA on pancreatic cancer cells and provide evidence that this mechanism occurs also in vivo. Our results also display that ASA inhibits the expression of GSK-3 $\beta$ downstream genes, $\mathrm{Bcl}-2$ and cyclin D1. Of note, the anti-apoptotic Bcl-2 plays an important role in the development of many chemo- 
therapy resistances in cancer cells. It impairs the mitochondrial apoptotic function by neutralizing the proapoptotic Bcl-2 family members such as Bax and Bak ${ }^{[23]}$. Thereby, Bcl-2 may be the effecter molecule of ASA to regulate gemcitabine-induced cytotoxicity and apoptosis. Cyclin D1 is overexpressed in human pancreatic cancer tissue and inversely correlated with patient survival ${ }^{[24]}$. It governs the checkpoint of $G_{1}$ to $S$ phase progression $^{[25]}$ and is always responsible for the aberrant cell cycle in tumor cells ${ }^{[26]}$. In our work, suppression of cylcin D1 expression by ASA seems to contribute to the cell cycle retardation and proliferation reduction in PANC-1 cells.

Admittedly, GSK-3 $\beta$ can also regulate cyclin D1 at the posttranslational level by phosphorylating cyclin D1 on T286 and inducing its rapid turnover ${ }^{[25]}$. In the present work, we display that ASA significantly inactivates GSK-3 $\beta$ and suppresses cyclin D1 at the transcription level in pancreatic cancer cells, which is, to our knowledge, never reported before.

Akt and PP2A pathways are implicated in the activation of GSK-3 $\beta$. PP2A dephosphorylates and activates GSK-3 $\beta^{[27]}$ while Akt can inactivate GSK-3 $\beta$ by phosphorylating GSK-3 $\beta$ at Ser9 ${ }^{[28]}$. Alternatively, PP2A can act upstream of Akt pathway to indirectly regulate GSK-3 $\beta$ signaling ${ }^{[15]}$. However, our results demonstrate that only Akt activation is involved in the inactivation of GSK-3 $\beta$ by ASA in PANC- 1 cells, which takes place independently of PP2A pathway. Concerns may be aroused that Akt activation renders the resistance of pancreatic carcinoma against anticancer drugs ${ }^{[29,30]}$. In fact, Akt does not seem to be involved in gemcitabine resistance of human pancreatic carcinoma cell lines. It is reported that neither did the basal Akt activity correlate with the sensitivity towards gemcitabine treatment, nor did the inhibition of Akt by LY294002 alter gemcitabine-induced apoptosis ${ }^{[2]}$. Thus ASA is not likely to confer chemoresistance to the current clinical regimen for pancreatic carcinomas.

In conclusion, our results show that ASA inhibits proliferation and potentiates the apoptosis-inducing effect of gemcitabine in pancreatic cancer cells, probably by inhibiting activation of GSK-3 $\beta$ and the expression of its regulated targets. Thus, the traditional agent ASA may prove to be a novel candidate to be used in combination with gemcitabine for the chemotherapy of pancreatic carcinoma.

\section{Acknowledgements}

This work was supported by Key program, National Natural Science Foundation of China (№ 30830111) and National Natural Science Foundation of China (№ 330801408).

\section{Author contribution}

Yan-qiu OU and Guang-mei YAN designed research; Yanqiu OU, Peng-xin QIU, Yi-jun HUANG, Jun XIE, Song-min HE, Xiao-ke ZHENG, Tian-dong LENG, Dong XU performed research; Yan-qiu OU, Wen-bo ZHU, Tian-dong LENG, and Guang-mei YAN analyzed data; Yan-qiu OU, Wen-bo ZHU, Yan-LI wrote the paper.

Supplementary information is available at NPG website.

\section{References}

1 Lowenfels AB, Maisonneuve P. Epidemiology and prevention of pancreatic cancer. Jpn J Clin Oncol 2004; 34: 238-44.

2 Arlt A, Gehrz A, Muerkoster S, Vorndamm J, Kruse ML, Folsch UR, et al. Role of NF-kappaB and Akt/PI3K in the resistance of pancreatic carcinoma cell lines against gemcitabine-induced cell death. Oncogene 2003; 22: 3243-51.

3 Li L, Aggarwal BB, Shishodia S, Abbruzzese J, Kurzrock R. Nuclear factor-kappaB and IkappaB kinase are constitutively active in human pancreatic cells, and their down-regulation by curcumin (diferuloylmethane) is associated with the suppression of proliferation and the induction of apoptosis. Cancer 2004; 101: 2351-62.

4 Reddy LH, Marque PE, Dubernet C, Mouelhi SL, Desmaele D, Couvreur P. Preclinical toxicology (subacute and acute) and efficacy of a new squalenoyl gemcitabine anticancer nanomedicine. J Pharmacol Exp Ther 2008; 325: 484-90.

5 Ougolkov AV, Bone ND, Fernandez-Zapico ME, Kay NE, Billadeau DD. Inhibition of glycogen synthase kinase-3 activity leads to epigenetic silencing of nuclear factor kappaB target genes and induction of apoptosis in chronic lymphocytic leukemia B cells. Blood 2007; 110: 735-42.

6 Ougolkov AV, Fernandez-Zapico ME, Savoy DN, Urrutia RA, Billadeau DD. Glycogen synthase kinase-3beta participates in nuclear factor kappaB-mediated gene transcription and cell survival in pancreatic cancer cells. Cancer Res 2005; 65: 2076-81.

7 Gilroy DW. The role of aspirin-triggered lipoxins in the mechanism of action of aspirin. Prostaglandins Leukot Essent Fatty Acids 2005; 73 : 203-10.

8 Dihlmann S, Klein S, Doeberitz Mv MK. Reduction of beta-catenin/ T-cell transcription factor signaling by aspirin and indomethacin is caused by an increased stabilization of phosphorylated beta-catenin. Mol Cancer Ther 2003; 2: 509-16.

9 Sclabas GM, Uwagawa T, Schmidt C, Hess KR, Evans DB, Abbruzzese $\mathrm{JL}$, et al. Nuclear factor kappa B activation is a potential target for preventing pancreatic carcinoma by aspirin. Cancer 2005; 103 : 2485-90.

10 Rejiba S, Wack S, Aprahamian M, Hajri A. K-ras oncogene silencing strategy reduces tumor growth and enhances gemcitabine chemotherapy efficacy for pancreatic cancer treatment. Cancer Sci 2007; 98: 1128-36.

11 Pan J, Quintas-Cardama A, Kantarjian HM, Akin C, Manshouri T, Lamb P, et al. EXEL-0862, a novel tyrosine kinase inhibitor, induces apoptosis in vitro and ex vivo in human mast cells expressing the KIT D816V mutation. Blood 2007; 109: 315-22.

12 Jenkins JK, Suwannaroj S, Elbourne KB, Ndebele K, McMurray RW. 17-Beta-estradiol alters Jurkat lymphocyte cell cycling and induces apoptosis through suppression of $\mathrm{Bcl}-2$ and cyclin $\mathrm{A}$. Int Immunopharmacol 2001; 1: 1897-911.

13 Chandler NM, Canete JJ, Callery MP. Increased expression of NFkappa B subunits in human pancreatic cancer cells. J Surg Res 2004; 118: 9-14.

14 Dong YW, Wang XP, Wu K. Suppression of pancreatic carcinoma growth by activating peroxisome proliferator-activated receptor gamma involves angiogenesis inhibition. World J Gastroenterol 2009; 15: 441-8.

15 Lin CF, Chen CL, Chiang CW, Jan MS, Huang WC, Lin YS. GSK-3beta acts downstream of PP2A and the PI3-kinase-Akt pathway, and upstream of caspase-2 in ceramide-induced mitochondrial apoptosis. J Cell Sci 2007; 120: 2935-43.

16 Alessi DR, James SR, Downes CP, Holmes AB, Gaffney PR, Reese CB, 
et al. Characterization of a 3-phosphoinositide-dependent protein kinase which phosphorylates and activates protein kinase Balpha. Curr Biol 1997; 7: 261-9.

17 Kunnumakkara AB, Guha S, Krishnan S, Diagaradjane P, Gelovani J, Aggarwal BB. Curcumin potentiates antitumor activity of gemcitabine in an orthotopic model of pancreatic cancer through suppression of proliferation, angiogenesis, and inhibition of nuclear factor-kappaBregulated gene products. Cancer Res 2007; 67: 3853-61.

18 Moertel CG, Ahmann DL, Taylor WF, Schwartau N. Aspirin and pancreatic cancer pain. Gastroenterology 1971; 60: 552-3.

19 Iconomou G, Kalofonos HP, Koutras AK, Vagenakis AG, Rigas B. Pilot study of nitric oxide-donating aspirin in patients with pancreatic cancer pain. J Support Oncol 2006; 4: 168.

20 Ricchi P, Palma AD, Matola TD, Apicella A, Fortunato R, Zarrilli R, et al. Aspirin protects Caco-2 cells from apoptosis after serum deprivation through the activation of a phosphatidylinositol 3-kinase/AKT/ p21Cip/WAF1pathway. Mol Pharmacol 2003; 64: 407-14.

21 Dragovich T, Burris H 3rd, Loehrer P, Von Hoff DD, Chow S, Stratton $\mathrm{S}$, et al. Gemcitabine plus celecoxib in patients with advanced or metastatic pancreatic adenocarcinoma: results of a phase II trial. Am J Clin Oncol 2008; 31:157-62.

22 Ougolkov AV, Fernandez-Zapico ME, Bilim VN, Smyrk TC, Chari ST, Billadeau DD. Aberrant nuclear accumulation of glycogen synthase kinase-3beta in human pancreatic cancer: association with kinase activity and tumor dedifferentiation. Clin Cancer Res 2006; 12 : 5074-81.
23 Ikegaki N, Katsumata M, Minna J, Tsujimoto Y. Expression of bcl-2 in small cell lung carcinoma cells. Cancer Res 1994; 54: 6-8.

24 Kornmann M, Ishiwata T, Itakura J, Tangvoranuntakul P, Beger $\mathrm{HG}$, Korc M. Increased cyclin D1 in human pancreatic cancer is associated with decreased postoperative survival. Oncology 1998; 55: 363-9.

25 Alao JP. The regulation of cyclin D1 degradation: roles in cancer development and the potential for therapeutic invention. Mol Cancer 2007; 6: 24.

26 Vermeulen K, Van Bockstaele DR, Berneman ZN. The cell cycle: a review of regulation, deregulation and therapeutic targets in cancer. Cell Prolif 2003; 36: 131-49.

27 Ivaska J, Nissinen L, Immonen N, Eriksson JE, Kahari VM, Heino J. Integrin alpha 2 beta 1 promotes activation of protein phosphatase $2 \mathrm{~A}$ and dephosphorylation of Akt and glycogen synthase kinase 3 beta. Mol Cell Biol 2002; 22: 1352-9.

28 Cross DA, Alessi DR, Cohen P, Andjelkovich M, Hemmings BA. Inhibition of glycogen synthase kinase-3 by insulin mediated by protein kinase B. Nature 1995; 378: 785-9.

29 Wendel HG, De Stanchina E, Fridman JS, Malina A, Ray S, Kogan S, et al. Survival signalling by Akt and elF4E in oncogenesis and cancer therapy. Nature 2004; 428: 332-7.

30 di Palma A, Matarese G, Leone V, Di Matola T, Acquaviva F, Acquaviva $\mathrm{AM}$, et al. Aspirin reduces the outcome of anticancer therapy in Meth A-bearing mice through activation of AKT-glycogen synthase kinase signaling. Mol Cancer Ther 2006; 5: 1318-24. 